Article

\title{
Does Urban Industrial Agglomeration Lead to the Improvement of Land Use Efficiency in China? An Empirical Study from a Spatial Perspective
}

\author{
Wei Han ${ }^{1,2}$, Ying Zhang ${ }^{3}$, Jianming Cai ${ }^{1,2, *}$ and Enpu Ma ${ }^{1,2}$ \\ 1 Institute of Geographic Sciences and Natural Resources Research, Chinese Academy of Sciences, \\ Beijing 100101, China; han_wei1987@126.com (W.H.); maenpu2015@sina.com (E.M.) \\ 2 School of Resources \& Environment, University of Chinese Academy of Sciences, Beijing 100049, China \\ 3 School of Management, Minzu University of China, Beijing 100081, China; zhangyingmuc@163.com \\ * Correspondence: caijm@igsnrr.ac.com; Tel.: +86-136-812-15731
}

Received: 18 January 2019; Accepted: 11 February 2019; Published: 14 February 2019

check for updates

\begin{abstract}
Industrial agglomeration is an important economic phenomenon in urban areas and has significant effects on land use efficiency (LUE) due to external economies of scale. A bourgeoning body of literature has investigated the effects of industrial agglomeration. However, the relationship between industrial agglomeration and land use efficiency has rarely been discussed in China. To fill this gap, this study aims to explore the effects of industrial agglomeration on LUE and the characteristics of its spatial distribution. In this study, the spatial effects of industrial agglomeration of 12 detailed sectors on LUE are estimated through the geographical weighted regression model. Socioeconomic data of 289 prefecture-level cities in China are utilized for the analysis. Results show several important findings. First, spatial effects of industrial agglomerations on LUE are evident in three grand city clusters, i.e. the Beijing-Tianjin-Hebei Region, the Yangtze River Delta, and the Pearl River Delta. Second, spatial patterns and distributions of industrial agglomeration effects on LUE vary across regions. Third, the significance of industrial agglomeration effects on LUE between 2-digit industrial sectors is different. The merits of this study lie in three aspects: First, a theoretical framework is explored to analyze the impacts of industrial agglomeration on LUE based on the expanded Cobb-Douglas production function; Second, the impacts of industrial sectors on LUE are estimated from a spatial perspective; Third, some policy implications for a more economically efficient urban spatial development are suggested.
\end{abstract}

Keywords: Urban industrial agglomeration; land use efficiency; geographically weighted regression model; spatial distribution; city cluster

\section{Introduction}

After the fundamental reform and opening-up initiated in late 1978, China's industrial development has been making unprecedented achievements in terms of scales and growth rate. In 2016, Chinese gross domestic product (GDP) reached 12.24 trillion US dollars, which is more than 80 times of that in 1978. However, the induced disorder urban sprawl has been a serious problem in urban China in general and in large cities in particular. Cities have been facing challenge by the contradiction between the growing demand for construction land and less enough supply of land quota during the fast process of urbanization [1]. Therefore, improving urban land use efficiency (LUE) in cities is crucial for building a more economically efficient spatial development pattern by smart industrial agglomeration, and addressing the land supply challenge in the new urbanization aspiration in the transition of China. 
Land use efficiency is an important measurable indicator reflecting the relationship between land input and economic output [1]. The definition of LUE is different in different domains. From the perspective of agriculture, LUE is defined as the crop yield per unit on farm land by considering factors such as nutrition, food safety, cultivated technology and others [2]. From the perspective of industrial development, LUE is defined as the industrial output per industrial land area [1]. When considering environmental protection and complexity of cities, some scholars argued that LUE should be defined as the efficiency of an input-output process estimated by an evaluation system including land elements, energy consumption, and others [3]. In view of urban space, the disordered urban expansion is partially due to inappropriate urban industrial planning and extensive land use. Because of reliance on unbalanced and unsustainable industries, many cities are perplexed by a situation that urban land is costly and is developed at a relatively low efficiency [1]. Therefore, focusing on improving the economically efficiency of urban development, this study employed the definition of LUE as "average economic output per square kilometer of urban built land" [4].

The definition of LUE is important for consummating urban planning and management. Controlling disorderly urban expansion is an important theme for urban planning and management in practice [5]. Therefore, increasing economic output in urban areas is a feasible means to realize this planning objective. To achieve a best economic overall layout of a city, LUE and its influencing factors should be recognized as key references-for policy making in the land use planning and industrial planning [3]. For example, an industrial project with a high LUE should be rendered a high priority for deployment and development. Expansions of construction should be effectively controlled to avoid inefficient land use. At the same time, the regional planning of a country should fully consider the spatial heterogeneity of LUE in order to enact region-tailed planning policies.

To reliably estimate the economic effects of industrial agglomeration on LUE from a spatial perspective, the spatial distribution of industrial agglomerations and LUE is firstly investigated. Secondly, the spatial impacts of industrial agglomeration at detailed industrial sectors on LUE at the prefectural-city level is explored by using the data of 289 prefecture level cities in China through the geographically weighted regression (GWR) model. Thirdly, some relevant policy suggestions for economically efficient urban spatial development are recommended. The rest of this paper is structured as follows: Section 2 narrates the literature review. Section 3 describes the data and methodology. Section 4 presents the results and discussion. Section 5 summarizes the findings and policy implications.

\section{Literature Review}

\subsection{Industrial Agglomeration}

Industrial agglomeration is defined as a cluster of companies in one or some interconnected industries concentrated in a certain area, which is united by common interests and complementary $[6,7]$. Specialization and diversity are the two main agglomeration economies [8-11] formed the theory of industrial agglomeration and pointed out the external economy of scale of specialization. Externalities are distinguished from the internal economies of scale and mainly involve labor pooling, specialized input production and knowledge outflow [12]. External economies of scale are the necessary consequences for spatial clustering of industries. Knowledge spillover is the most important externality of industrial agglomeration that leads to innovations [13]. A typical case of specialization is the cluster of small- and medium-sized enterprises in Central and Northeastern Italy known as the "Third Italy' [14]. Highly specialized division of labor force is formed due to the emergence of external economies. Another kind of agglomeration, namely, diversity, was put forward by [15]. He suggested that knowledge spillover, which contributes to innovation, is rooted in an environment of diversified production structures. A sample case of diversification is the growth of Detroit's shipbuilding industry, which resulted in the growth of the city's automobile industry [16]. 
Agglomeration economies provide important theoretical underpinnings for many theories related to regional and urban development. For example, [17] proposed the industrial location theory and pointed out that the location of enterprise is decided by three main factors, namely, transport cost, labor cost, and agglomeration based on the minimization of costs or maximization of profits [18]. When the benefits of gathering exceed the transport and labor costs, industries tend to concentrate; when the transport and labor costs are more than the profits of agglomeration, industries tend to be centrifugal. Agglomeration can affect industrial productivity efficiency in accordance with its location. Both $[19,20]$ built the central place theory. This theory suggests that economic agglomerations are likely to emerge in high-tiered urban areas. Upper-tier cities usually have more convenient transportation, labor force, and investments that attract more industries, employment, and population. As a result, the agglomeration advantages of central places are continuously reinforced. The advantages of agglomeration are the reasons why upper-tier central places persistently remain at the top of the hierarchy [21]. With the rapid economic globalization in the late twentieth century, [6] focused on the industrial clusters that affected national competitiveness. He concluded that competition is better for innovation and spillovers of monopoly. The competitiveness of an industry was taken further to the international scope on the basis of Porter's Diamond Model. All these theories confirm that agglomeration affects the production within firms and the development of urban areas and national competitiveness. Externalities have a role on reducing production costs, improving innovation and enhancing total factor productivity [22-25].

In recent years, empirical studies have been carried out to analyze the relationship between industrial agglomeration and production efficiencies and development of firms, industries, urban areas and regions. By using firm-level data in China, [26] found that urbanization economies of inter-industry externalities play a positive impact on the product innovation of firms. [27] examined externalities in manufacturing by using firm-level census data in Morocco and found that external economies of scale of agglomeration affect production through total factor productivity and wage effects. At the industrial level, [28] recognized that high-tech-intensive industries are prone to benefit from the diversification of aggregates, whereas low-technology industries tend to benefit from specialization. [29] found that specialization and diversity have a negative impact on the growth of industrial sectors, whereas service sectors exhibit negative specialization and positive diversification effects.

At the urban and regional development levels, industrial agglomerations within cities exert varied impacts. On the one hand, some studies have recorded positive relationships between industrial agglomerations and economic development. [30] demonstrated the positive relationship between industrial clustering and economic development in East Asia particularly in China. [31] pointed out that specialization and diversification agglomerations have significantly positive effects on reducing energy efficiencies of the city itself and neighboring cities. On the other hand, negative relationships have also been concluded in some empirical studies. Using panel data, [32] found that specialized agglomeration has a negative impact on the value-added growth of Chinese provinces. [33] found that agglomeration has a negative impact on the development of regional periphery and the growth rate of income at the areas of periphery and clusters. Clearly, under different circumstances, industrial agglomerations can cause different effects. Thus, examining the effects of industrial agglomerations should depend on the specific situation and the different objects of analysis.

\subsection{Industrial Agglomeration and LUE}

Land resources are not economically and efficiently used in China as local governments usually pursue the expansion of city scales and size of economy. Under this condition, many industrial parks are built in China just as the showcase of government achievement but not necessarily for pure economic sense, which causes inefficient land use and waste of resources. LUE in most Chinese cities had shown a decline even in the eastern developed regions [34,35]. However, economically efficient land use is highly important as it is a good way to relieve the serious conflict among population, environment, and space. Exploring the characteristics of the relationship between 
industrial agglomeration and LUE is of great significance for the efficient integration between urban land use system and economic externalities [3]. Therefore, it is necessary to study whether industrial agglomerations in cities lead to efficient land use or rather produce negative diseconomy of land use.

The impacts of industrial agglomeration on LUE can be analyzed at three stages. First, when industries only concentrate in space but do not produce external economies of scale, the cost of total factor productivity may not be reduced but performs high because of the investment of land, labor and materials. Under this condition, LUE can be relatively low [3]. Second, when returns to economic scale by industrial clustering effects can obviously reduce urban average production costs, urban areas would contribute more output values and less input values than rural and peri-urban areas. Resources, such as land, can be used efficiently at this stage [36,37]. Third, the costs of production inputs, such as labour, land, and energy, will increase if an excessive agglomeration happens. This kind of aggregation is diseconomy and increases the total production cost, which may decrease the output efficiency of land [38,39].

Although a large amount of literature focuses on industrial agglomeration and its influence mechanism, little attention has been paid on whether industrial agglomeration improves LUE in China. Moreover, the different impacts between detailed industrial sectors are unclear. This study then can make its contribution to the literature in three aspects. First, a theoretical framework is explored to analyze the impacts of industrial agglomeration on LUE based on the expanded Cobb-Douglas production function. Second, the impacts of detailed industries on LUE are estimated from a spatial perspective. Third, policy implications for effective land use are suggested.

\section{Data and Methodology}

\subsection{Theoretical Framework Analysis}

LUE is mainly influenced by several parameters. From the opening-up of China, expansion of urban land and increase of construction land are mainly caused by the process of industrialization, globalization, urbanization, and marketization [40-45]. Therefore, this study tries to explore the theoretical framework of LUE from these four aspects.

LUE is significantly influenced by industrialization. Industrialization has greatly influenced landscapes both in rural and urban areas [46]. During the process of industrialization, rural area is developed to urban area and farmland is changed into construction land. In order to improve the industrial development, infrastructural facilities such as of traffics, research and development and communication platforms should be considered into the urban planning. In another aspect, industrial land price is usually low in the industrial parks or economic development zone [5]. Therefore, local government and enterprises are inclined to promote industrial agglomeration. External economies of scale is emerged within the industrial agglomeration [12], which reflects in space as the prosperity of land output.

Globalization has been confirmed that it is an important driving force for urban land restructuring [47]. With the opening-up policy of China since 1979, foreign direct investment (FDI) stimulated the emergence of rural industrialization, exo-urbanization, and an export-oriented economy especially in coastal areas [40]. In order to attract foreign investment, infrastructure, research and development facilities and communication convenience are significantly improved [48]. FDI leads to the emergence of industrial zones in peri-urban areas, changing landscapes of urban areas, and improving the economically efficient output of land.

Urbanization is another important factor leading to changes of LUE [41]. With the process of urbanization, rural area is transferred to urban area, resulting in the remarkable expansion of urban scales in China. At the same time, a large amount of rural population has been migrating to cities to seek job opportunities. On the one hand, new urban residents are important labor force for the city. On the other hand, they are consumers with large consumption demands for housing, education, transportation, and communication [49]. When formulating urban planning and management policy, 
the impacts of fast urbanization should be taken into consideration in order to achieve the economically efficient overall layout of a city.

Marketization also an important impetus for changes of urban land. During the rapid marketization in China, hierarchical government-controlled land system has been transferred to largely market-oriented [44]. In the process of marketization, land system reform is continually carried out. In rural areas, collective-owned construction land has been permitted to enter market and have equal rights and prices with urban state-owned land [50]. In urban area, land banking system and land bid invitation, auction and listing system are implemented [51,52]. These land systems have changed the capital investment environment both in rural and urban areas, improving the market mechanism in resource allocation and raising land values. The theoretical framework for urban LUE is shown in Figure 1.

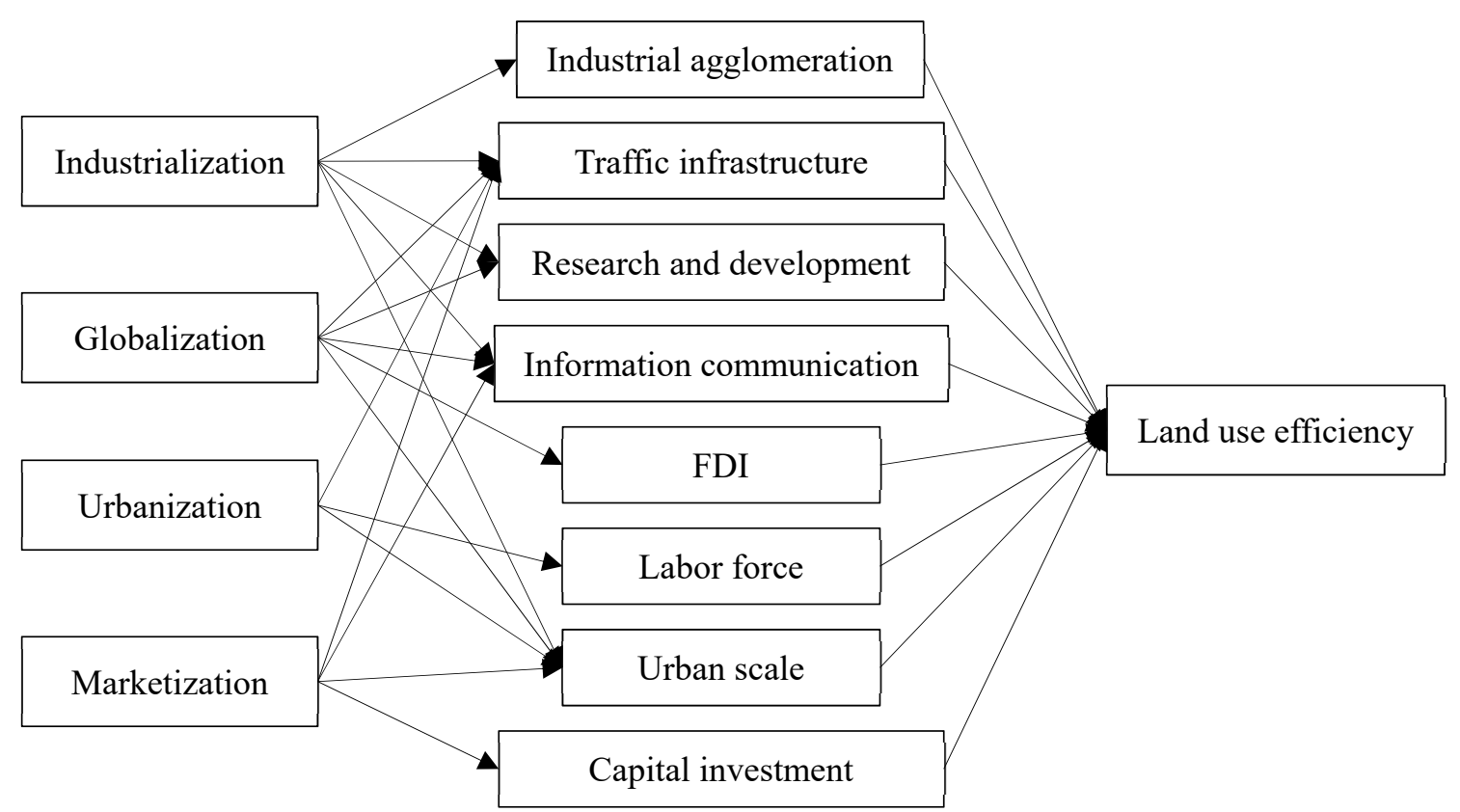

Figure 1. Theoretical framework of urban land use efficiency. FDI: foreign direct investment.

As discussed above, LUE in this study is calculated in terms of urban GDP per square kilometer of urban built land. The land use efficiency $L U E_{i}$ of city $i$ is calculated as

$$
L U E_{i}=G D P_{i} / L A_{i}
$$

where $G D P_{i}$ is the GDP of city $i$ and $L A_{i}$ is the built-up area of city $i$.

In the industrial agglomeration analysis, an expanded Cobb-Douglas production function is applied by many scholars to estimate agglomeration economies [23,38,53]:

$$
q_{i}=\theta_{i}\left(\left(n_{i} H_{i}\right)^{\beta} k_{i}^{1-\beta}\right)^{\alpha}\left(\frac{Q_{i}}{A_{i}}\right)^{(\lambda-1) / \lambda}
$$

where $q_{i}$ denotes the output per square kilometer of land (LUE), $\theta_{i}$ is the total factor productivity, $n_{i}$ is the employees per square kilometer of land, $H_{i}$ is the human capital, $k_{i}$ is the physical capital input per square kilometer of land and $Q_{i}$ and $A_{i}$ are the output and area of a city, respectively. In Equation (2), $\frac{Q_{i}}{A_{i}}$ expresses the spatial density of output. If $\lambda>1$, then spatial density shows positive externality, and if $\lambda<1$, then spatial density shows negative externalities. 
Therefore, $\left(\frac{Q_{i}}{A_{i}}\right)^{(\lambda-1) / \lambda}$ represents the externality of industrial agglomeration. To further measure the externalities of agglomeration economy, $L U E_{i}$ is used to represent $q_{i}$ and $\left(a g g l_{i}\right)^{\delta}$ is used to represent the externality of industrial agglomeration. Equation (2) can be expressed as follows:

$$
L U E_{i}=\theta_{i}\left(\left(\frac{N_{i}}{A_{i}} H_{i}\right)^{\beta}\left(\frac{K_{i}}{A_{i}}\right)^{1-\beta}\right)^{\alpha}\left(a g g l l_{i}\right)^{\gamma}
$$

where $N_{i}$ denotes urban employment and $K_{i}$ denotes physical capital stock.

Previous studies have concluded that infrastructure, human capital, foreign direct investment (FDI), capital investment, research and development and information communication are important factors affecting total factor productivity [22,54-57]. The total factor productivity can be calculated as follows:

$$
\theta_{i}=f(I N F, H C, F D I, C I, R D, I C)+\varepsilon_{i}
$$

where $i$ represents city; INF, HC, FDI, CI, RD and IC denote infrastructure, human capital, FDI, capital investment, research and development and information communication, respectively; and $\varepsilon$ is a random disturbance term. On the basis of Equations (3) and (4), the econometric model of the relationship between industrial agglomeration and LUE can be given as follows:

$$
\ln L U E_{i}=\gamma \operatorname{lnagglo} o_{i}+\delta \ln X_{i}+\varepsilon_{i}
$$

where LUE is land use efficiency, agglo is the degree of industrial clustering and $X$ represents other important factors influencing LUE. In according with the theoretical framework of LUE, these factors include human capital, urban scale, infrastructure, FDI, capital investment environment, research and development, and information communication.

\subsection{GWR Model}

As China covers a large territory, its economic development may show strong characteristics of spatial heterogeneity. Thus, whether industrial agglomeration distribution and LUE show spatial differences among the eastern, central, and western areas is a common question. For robust empirical findings, spatial difference should be considered in estimations. [58] proposed the GWR method to solve the spatial non-stationarity problem. Compared with the traditional average and global model, GWR model allows different parameters to exist in different spaces. In this way, the good performance of GWR model has been demonstrated in studies, and more reliable results have been obtained than those in traditional ordinary least squares (OLS) for estimations on subjects with spatial heterogeneity characteristics [59-61]. Therefore, the GWR model is used in this study to reveal the spatial variations of industrial agglomeration effects on LUE. The GWR model is expressed as follows:

$$
y_{i}=\beta_{0}\left(u_{i}, v_{i}\right)+\sum_{k=1}^{p} \beta_{k}\left(u_{i}, v_{i}\right) x_{i k}+\varepsilon_{i}
$$

where $y_{i}$ is the dependent variable, in this case the LUE at location $i, \beta_{0}\left(u_{i}, v_{i}\right)$ denotes the intercept coefficient at location $i, x_{i k}$ is the value of the $k$ th explanatory variable at location $i, \beta_{k}\left(u_{i}, v_{i}\right)$ is the $k$ th local regression coefficient for the $k$ th explanatory variable, $\left(u_{i}, v_{i}\right)$ is the projected coordinates of location $i$ and $\epsilon_{i}$ is a random error term. Stated in matrix notation, the parameters of the model are estimated by the following equation:

$$
\hat{\beta}(i)=\left(X^{T} W(i) X\right)^{-1} X^{T} W(i) y
$$

where $\hat{\beta}$ denotes an estimate for $\beta$ and $W(i)$ is an $n \times n$ spatial weighting matrix where diagonal elements represent the spatial weight of each location to location $i$ and off-diagonal elements are 0 . 
As the bandwidth of the kernel function chosen is sensitive to the regression of GWR, the optimal value of bandwidth should be determined [62]. By using the spatial weighting function, an adaptive bi-square function is applied to generate the geographic weights of each observation. Bi-square kernel has a clear-cut range where kernel weighting is non-zero and is suitable when local extents for model fitting need to be clarified. Adaptive bi-square function permits the bandwidth to increase its size when sample points are sparse and decrease the size when observations are dense [63]. As the density of city in China change greatly in space, so the adaptive bi-square function is adopted in this study. The bi-square function can be expressed as follows:

$$
w_{i j}=\left(1-d_{i j}^{2} / b\right)^{2}\left(\text { if } d_{i j} \leq \theta_{i(k)}, \text { otherwise } w_{i j}=0\right)
$$

where $i$ is the regression point index, $j$ is the locational index, $w_{i j}$ is the weight value of observation at location $j$ for estimating the coefficient at location $i, d_{i j}$ is the Euclidean distance between $i$ and $j$ and $b$ is an adaptive bandwidth. The optimal bandwidth can be determined by cross-validation (CV) $[64,65]$ :

$$
C V=\sum_{i=1}^{n}\left[y_{i}-\hat{y}_{\neq i}(b)\right]^{2}
$$

where $\hat{y}_{\neq i}$ is the fitted value of $y_{i}$ and the corresponding $b$ is the optimal bandwidth when the CV is minimum.

\subsection{Moran's I}

The spatial autocorrelation and heterogeneity of observations may contain traditional global estimation and lead to biased results. Before using the GWR model, whether spatial autocorrelation occurs in the variables should be estimated. Moran's index (Moran's I) is chosen to represent the global spatial autocorrelation of LUE. The formula of Moran's I can be expressed as follows:

$$
\text { Moran's } I=\frac{n}{\sum_{i=1}^{n} \sum_{j=1}^{n} W_{i j}} \times \frac{\sum_{i=1}^{n} \sum_{j=1}^{n} W_{i j}\left(x_{i}-\bar{x}\right)\left(x_{j}-\bar{x}\right)}{\sum_{i=1}^{n}\left(x_{i}-\bar{x}\right)^{2}}
$$

where $x_{i}$ is the observation in the $i$ th city, $x_{j}$ is the observation in the $j$ th city, $W_{i j}$ represents the spatial weight of adjacent units, $\bar{x}$ represents the mean of $x_{i}$ or $x_{j}$ and $n$ is the total number of cities. The value of Moran's I is between -1 and 1 . The correlation is positive when the value is greater than 0 , which indicates that urban LUE shows a spatial positive correlation. The correlation is negative when the value is close to -1 , which means that urban LUE represents spatial negative correlation. The closer the value to 1 , the stronger the agglomeration effect is, whereas the closer the value to -1 , the stronger the diffusion effect is. When Moran's I is 0 , no spatial relationship exists.

The proposed methodologies including expanded Cobb-Douglas production function, GWR model and Moran's I improve city planning. First, when using expanded Cobb-Douglas production function, factors including industrialization, globalization, urbanization, and marketization which are influencing urban land output are all considered in the regression. In this way, the impacts of industrial agglomeration on LUE would be estimated more realistically than only without considering these factors, which will have practical meaning when doing urban planning. Second, indicator of Moran's I shows that if LUE has a spatial correlation, making the regression more robust when using GWR model. Third, regional differences are fully considered in the GWR model, which is suitable for the economic development in China. When doing the regional planning of the whole country, planning policies for regional leading industries and development direction will be more practical considering the spatial differences of LUE. 


\subsection{Independent Variables}

\subsubsection{Degree of Industrial Agglomeration}

Several indicators have been used to measure the degree of industrial spatial concentration, such as location quotient (LQ), location Gini coefficient (LGC), concentration ratio (CR), Herfindahl index and Ellison-Glaeser (EG) index. [12] proposed that LQ and CR emphasize industrial agglomeration in different regions, whereas the EG and LGC focus on different kinds of industrial agglomeration in a certain area. Following the practice of [29], this study adopts the LQ indicator to explore the spatial differences of the impacts of industrial agglomeration on LUE. LQ is estimated as follows:

$$
L Q_{i j}=\frac{e_{i j} / e_{j}}{E_{i} / E}
$$

here $L Q_{i j}$ is the LQ of the $i$ th sector in the $j$ th location; $e_{i j}$ and $E_{i}$ denote the employment of $i$ th sector of the $j$ th city and the whole country, respectively; and $e_{j}$ and $E$ denote the total employment of the $j$ th city and the whole country, respectively.

This study focuses on the economic effect of industrial agglomeration in the urban setting. Thus, the employment of the $i$ th sector of the $j$ th city represents the employment of the $i$ th sector in the built up area of the $j$ th city. With data availability, 12 detailed sectors are chosen in this study, namely, agro-industry; manufacturing; electricity and gas; construction; wholesale and retail trade; transport, storage and post services; hotel and catering services; information and software services; financial services; real estate; leasing and business services; and scientific research and technical services, as shown in Table 1. Agriculture in built up area usually concentrates in peri-urban areas and performs as urban agriculture [66-68]. This sector provides multiple functions of leisure, ecological protection and food security, which are important components of urban industries [66-68]. Therefore, agro-industry is used in this study to represent this scenario.

Table 1. Industrial sectors investigated.

\begin{tabular}{cc}
\hline Sector & Abbreviation \\
\hline Agro-industry & Aggro_agro \\
Manufacturing & Aggro_manu \\
Electricity and gas & Aggro_elec \\
Construction & Aggro_cons \\
Wholesale and retail trade & Aggro_whol \\
Transport, storage and post services & Aggro_trans \\
Hotel and catering services & Aggro_hotel \\
Information and software services & Aggro_infor \\
Financial services & Aggro_finan \\
Real estate & Aggro_real \\
Leasing and business services & Aggro_leas \\
Scientific research and technical services & Aggro_scien \\
\hline
\end{tabular}

\subsubsection{Description of Other Independent Variables}

As reviewed in the theoretical framework analysis, stylized factors also significantly affect LUE. Such factors include human capital, urban scale, infrastructure, FDI, capital investment environment, research and development, and information communication of the city. To improve estimation robustness, an extended pool of variables is included into the estimation to represent the influential factors (Table 2). 
Table 2. Descriptions of other independent variables.

\begin{tabular}{ccc}
\hline Factors & Indicators & Unit \\
\hline Human capital & Income per employee (IPE) & Yuan per person \\
Urban scale & Area of built district (ABD) & - \\
Infrastructure & Density of road network (DRN) & - \\
FDI & Foreign direct investment (FDI) & 10 thousand yuan \\
& Investment in fixed assets (IFA) & 10 thousand yuan \\
Capital investment environment & Loan-deposit ratio (LDR) & - \\
& Price of land transferring (PLT) & yuan $/ \mathrm{m}^{2}$ \\
Research and development & Ratio of education and technology expenditure on revenue (RETE) & - \\
Information communication & Number of universities (NU) & unit \\
& Revenue from telecommunication services (RTS) & 10 thousand yuan \\
& Number of internet access subscribers (NIAS) & 10 thousand households \\
\hline
\end{tabular}

This study covers all the 289 prefecture-level cities in China. Data are respectively sourced from the China City Statistical Yearbook (2017), China Urban Construction Statistical Yearbook (2017), China Statistical Yearbook (2017) and National Economic and Social Development bulletin of prefecture-level cities.

\section{Results and Discussions}

\subsection{Spatial Distribution of Industrial Agglomeration}

Figures 2 and 3 show the spatial distribution of LQ of 12 detailed sectors in China in 2016. Some industrial agglomerations are concentrated in specific regions, as shown in Table 3. According to the empirical results, two main characteristics explain the spatial distribution of industrial agglomeration.

First, the high-value agglomerations of LQ of the three main urban clusters (Beijing-Tianjin-Hebei Region, Yangtze River Delta, and Pearl River Delta) in China are significant. Industries agglomerating in the Beijing-Tianjin-Hebei (BTH) region include information and software services, financial services, real estate, leasing and business services and scientific research and technical services, with main functions in high technology and financial services, led and dominated by capital city Beijing. Manufacturing, construction, financial services and leasing and business services concentrate in the Yangtze River Delta (YRD). With Shanghai as the leader, YRD is the manufacturing and financial business center in China. The aggregation of manufacturing in the Pearl River Delta (PRD) is outstanding with very wide range. This reflects both the accumulation effect of FDI in the past and the attractiveness of PRD in driving manufacturing development as a global ideal place.

Second, high-value LQ in some regions is usually based on advantageous resources (Table 3). For example, agro-industry concentrates in the northeast region, including Liaoning, Jilin, and Heilongjiang provinces, where the traditional agricultural areas in China are located [69]. Electricity and gas industry concentrates in the northeast region, Inner Mongolia, and parts of the northwest and southwest regions, such as the Yunnan and Guangxi provinces [70,71]. Natural resources, such as wind, oil, gas, and coal, are also found in these areas [70,71]. Industrial agglomerations of real estate and hotels and catering services are evident in Hainan Province, where the famous International Tourism Island is backed by the Chinese government [72]. Accordingly, industries tend to agglomerate in economically developed areas and resource-rich areas. 
Table 3. Areas of high-value agglomeration of detailed industries.

\begin{tabular}{|c|c|}
\hline Detailed Industrial Sectors & Areas of High-Value Agglomeration \\
\hline Agro-industry & Northeast region \\
\hline Manufacturing & Eastern coastal areas \\
\hline Electricity and gas & Northern and southwestern regions \\
\hline Construction & Central and lower reaches of Yangtze River \\
\hline Wholesale and retail trade & Henan and Hubei provinces \\
\hline Transport, storage and post services & Ports and border cities in the northern region \\
\hline Hotel and catering services & Hainan province \\
\hline Information and software services & Beijing-Tianjin-Hebei region \\
\hline Financial services & Beijing-Tianjin-Hebei region, Yangtze River Delta and northeast region \\
\hline Real estate & Beijing-Tianjin-Hebei region, Pearl River Delta and Hainan province \\
\hline Leasing and business services & Beijing-Tianjin-Hebei region and Yangtze River Delta \\
\hline Scientific research and technical services & Beijing-Tianjin-Hebei region, northeast region and Gansu province \\
\hline
\end{tabular}
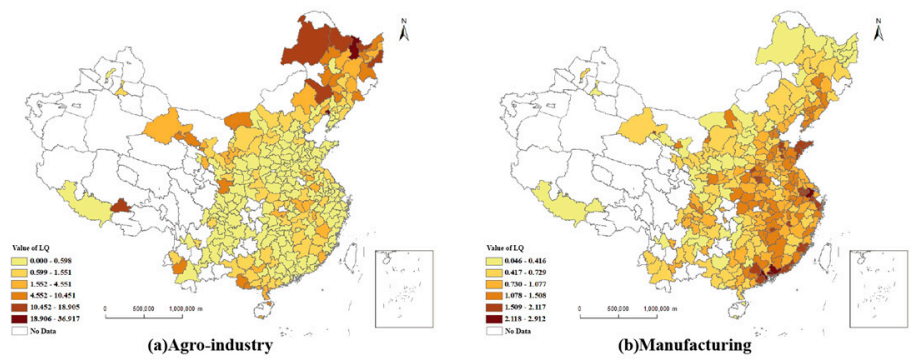

(b)Manufacturing

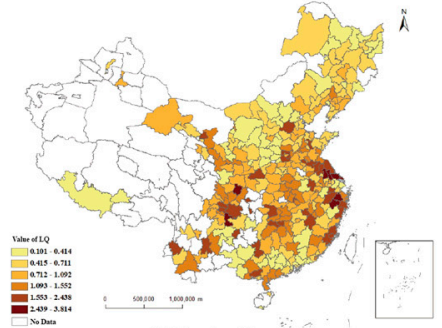

(d)Construction

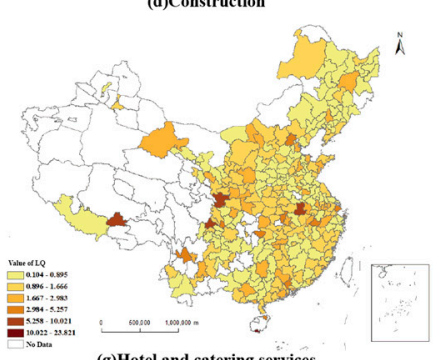

(g)Hotel and catering services

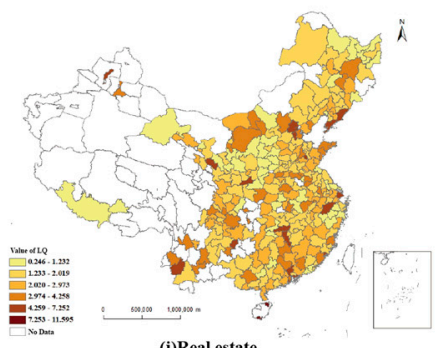

(j)Real estate

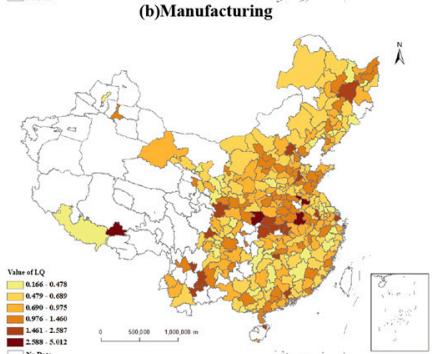

(e)Wholesale and retail trade
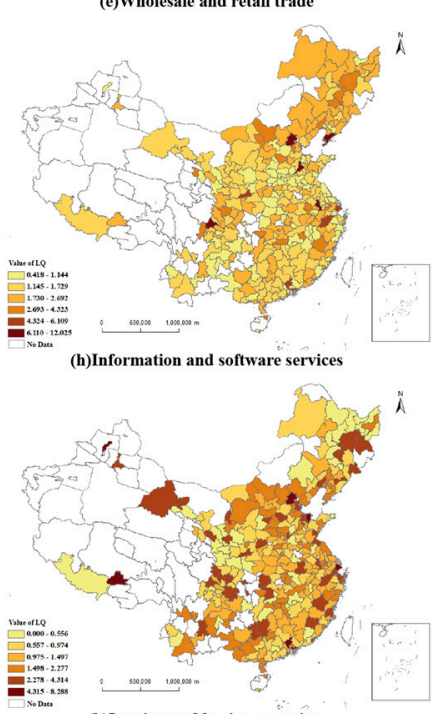

(k)Leasing and business services
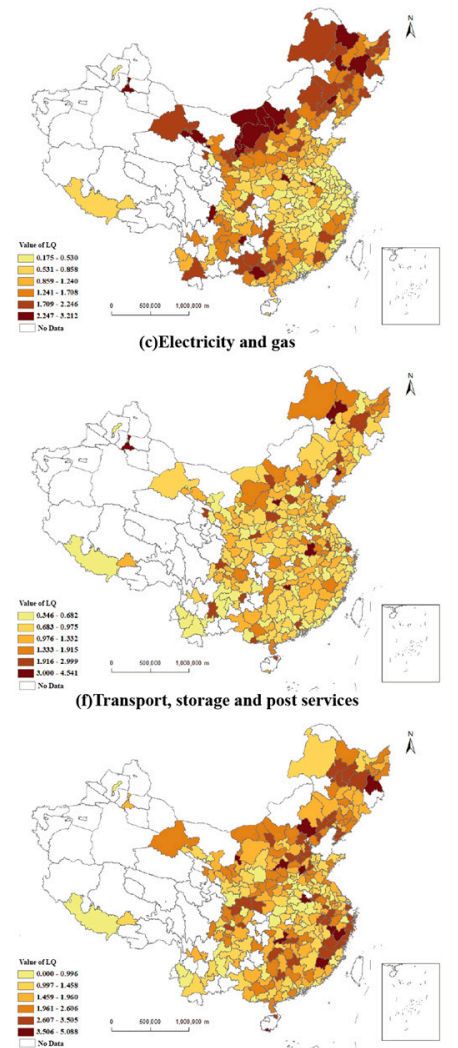

(i)Financial services

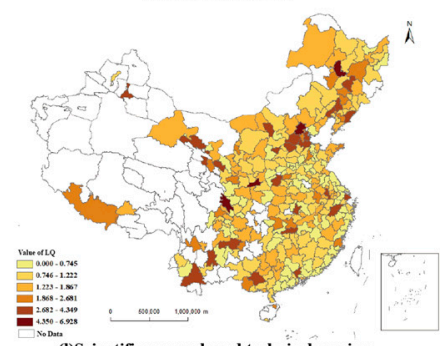

(I)Scientific research and technical services

Figure 2. Values of the location quotient (LQ) of detailed sectors. 


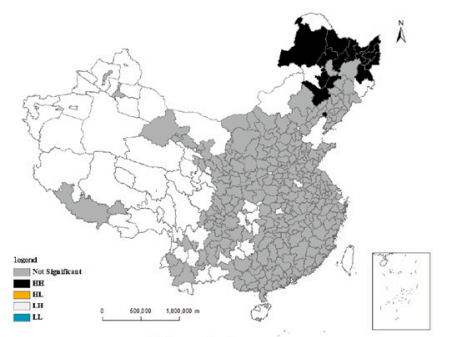

(a)Agro-industry

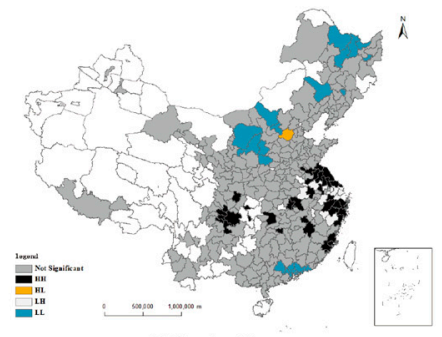

(d)Construction
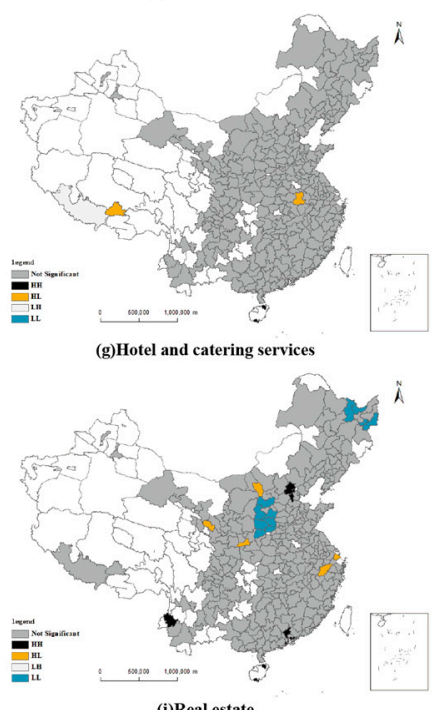

(j)Real estate

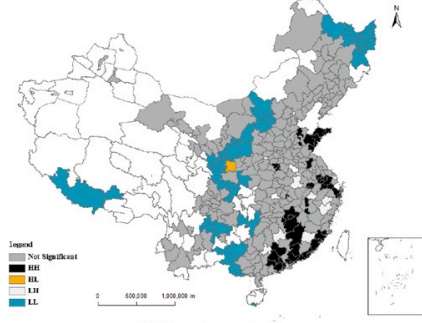

(b)Manufacturing

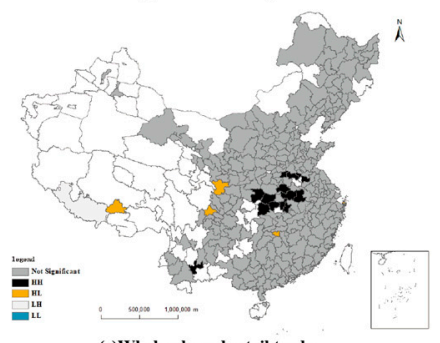

(e)Wholesale and retail trade
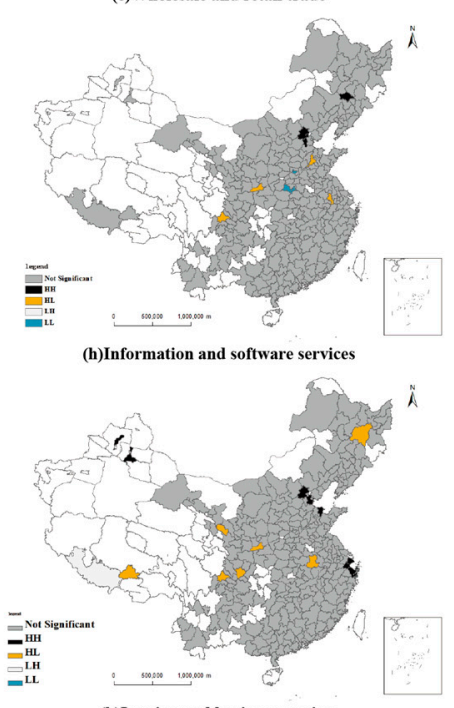

(k)Leasing and business services
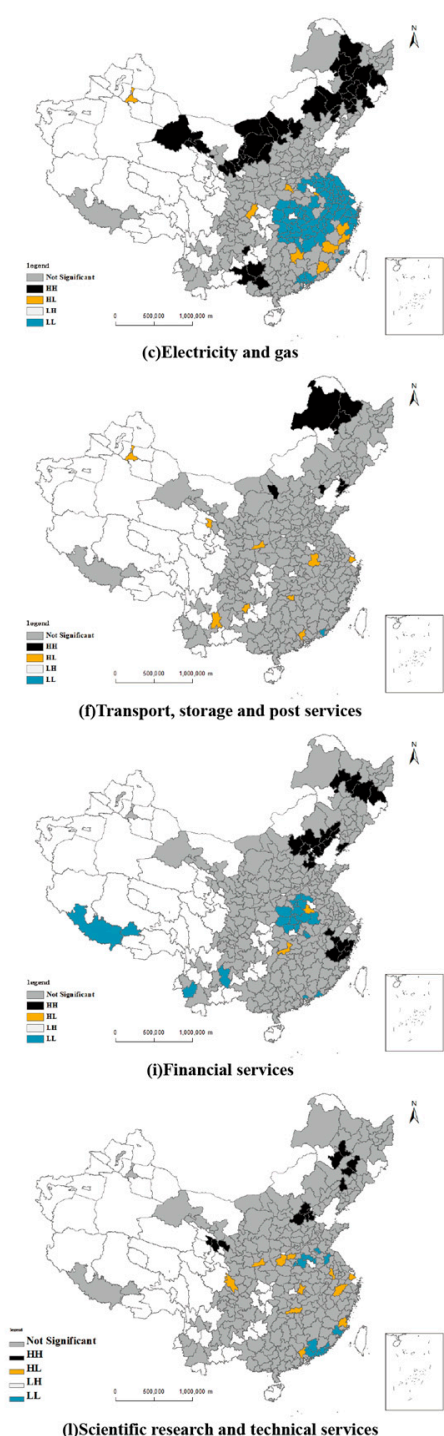

Figure 3. Clustering map of the LQ of detailed sectors.

\subsection{Spatial Distribution of LUE}

Figure 4 presents the LUE of 289 prefecture-level cities in China with a fairly large spatial heterogeneity. The characteristics can be summarized as follows:

First, a high LUE belt has been formed in the eastern coastal region from Beijing to Guangdong Province. This belt is mainly supported by the three main urban clusters of BTH, YRD, and PRD. High LUE in these urban clusters demonstrates that "the more intensive the city is, the higher is its land use efficiency" [35]. Since the Chinese economic reform in the late 1970s, eastern areas have experienced fast development induced mainly by FDI and its spillover effect. Growing population, urban economy and spatial expansion all require strong land use. Farm land in eastern areas is usually expropriated for urban development [73]. Tremendous market-driven land development during the urbanization process, and conflicts between land source and urban expansion all require sustainable development, which in return drives the efficient land use in the eastern areas [74].

Second, cities with high LUE in the central region mainly concentrate in city groups, including central Henan urban agglomeration, Changsha-Zhuzhou-Xiangtan city group, Poyang Lake city group and Wuhan city cluster. The city centers of these urban agglomerations, namely, Changsha, Wuhan, and Zhengzhou, have higher LUE than those of other cities in the central regions. Supported 
by preferential policies of the Chinese government, the development of urban agglomerations in the central region has great potential.

Third, cities with high values of LUE are scattered in the western region, which are mainly provincial capital cities, such as Chengdu, $\mathrm{Xi}^{\prime}$ an and $\mathrm{Xining}$. The western region has a less developed economy and lower urbanization level than cities in the central and eastern regions. Therefore, cities in the western region are sparse and show a relatively low value of LUE except for some provincial capital cities under the driven force of the go-west strategy initiated in late 1990s.

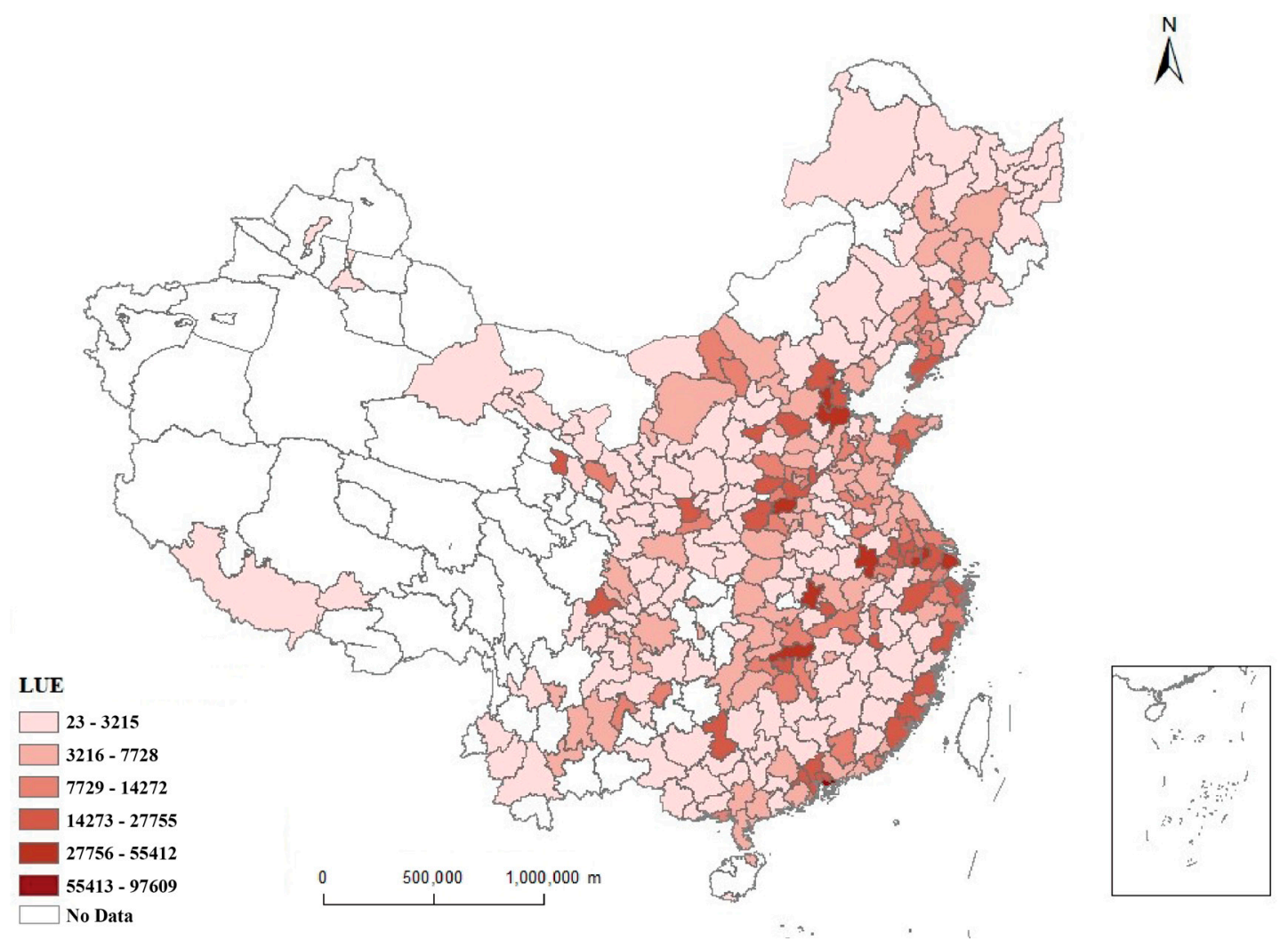

Figure 4. Spatial distribution of LUE.

\subsection{Spatial Autocorrelation Analysis}

As the dependent variable, the Moran's I of LUE was estimated. In accordance with the testing results by ArcGIS 10, Moran's I of LUE and its related indicators are shown in Table 4 . As shown in Table 4, accompanied by the z-score and p-value, Moran's I of LUE is positive at the $1 \%$ significance level. In other words, urban LUE has a spatial positive correlation in different cities. Therefore, GWR model can be further employed to test the spatial influence of industrial agglomeration on urban LUE.

Table 4. Parameters of Moran's index of land use efficiency (LUE).

\begin{tabular}{ccccc}
\hline & Moran's Index & Standard Deviation & z-Score & $p$-Value \\
\hline LUE & 0.1442 & 0.0002 & 9.2029 & 0.0000 \\
\hline
\end{tabular}

\subsection{Spatial Weighted Regression Analysis}

\subsubsection{Comparison of Global OLS and GWR Analyses}

Table 5 shows the descriptive statistics of variables. Among 289 cities, some industries show a large span value of agglomeration degree, which includes agro-industry, hotel and catering services, information and software services and real estate. By contrast, manufacturing, electricity and gas, 
construction, wholesale and retail trade, transport, storage and post services, financial services and leasing and business services have a small span value.

As shown in Table 6, global estimates provided by OLS are compared with local GWR tests in Equation (6). The regression results are shown in Table 5. Model 1 reports the average marginal effects of variables by using an OLS model, and Model 2 represents the results of the GWR model. The multicollinearity of variables has been tested, which reported that the VIF of all independent variables is less than 6. Therefore, further estimation can be made. Under Model 2, the change of parameters is divided into quarters. The lower quartile is the estimate at the 25th quartile, median is the 50th quartile and the upper quartile is the 75th quartile, which can reflect the range of the coefficient in space.

Overall, the results obtained by the OLS show that the adjusted $R^{2}$ is $78.7 \%$. By using the GWR model, local $R^{2}$ is significantly improved to $84.8 \%$ (25th quartile), $87 \%$ (50th quartile), and $89.7 \%$ (75th quartile). AIC also decreases from 572 to 521 . These changes mean that the fitted values of variables have improved by using the GWR model. Among the OLS regression results, the aggregation of agro-industry, electricity and gas, information and software services, and leasing and business services play a negative impact on LUE. The agglomeration of other sectors has a positive effect on LUE. At the same time, the results of the GWR model show that the effects of industrial agglomerations change greatly in space. Based on the spatial differences of socioeconomic development in China, GWR provides a better way to understand the spatial distribution of the relationship between industrial agglomeration and LUE.

Table 5. Descriptive statistics of variables.

\begin{tabular}{cccccc}
\hline Variables & Min. & Max. & Mean & Std. Dev & Observations \\
\hline LUE & 23.34 & $97,609.42$ & 6961.47 & 9571.04 & 289 \\
Aggro_agro & 0 & 36.92 & 1.45 & 3.69 & 289 \\
Aggro_manu & 0.05 & 2.91 & 0.89 & 0.5 & 289 \\
Aggro_elec & 0.18 & 3.21 & 1.11 & 0.66 & 289 \\
Aggro_cons & 0.1 & 3.81 & 0.91 & 0.62 & 289 \\
Aggro_whol & 0.17 & 5.01 & 0.87 & 0.56 & 289 \\
Aggro_trans & 0.35 & 4.54 & 1.07 & 0.65 & 289 \\
Aggro_hotel & 0.1 & 23.82 & 1.34 & 1.81 & 289 \\
Aggro_infor & 0.42 & 12.02 & 1.82 & 1.32 & 289 \\
Aggro_finan & 0 & 5.09 & 1.86 & 0.85 & 289 \\
Aggro_real & 0.25 & 11.59 & 2.25 & 1.39 & 289 \\
Aggro_leas & 0.08 & 8.29 & 1.44 & 1.12 & 289 \\
Aggro_scien & 0.09 & 6.93 & 1.32 & 0.98 & 289 \\
IPE & 36,793 & 122,749 & $59,017.48$ & $11,956.5$ & 289 \\
ABD & 10.9 & 1420 & 151.68 & 197.9 & 289 \\
DRN & 1.47 & 16.72 & 6.68 & 2.39 & 289 \\
FDI & 0 & $3,082,563$ & $97,635.25$ & $261,619.2$ & 289 \\
IFA & 762,998 & $172,000,000$ & $19,367,531$ & $19,089,936$ & 289 \\
LDR & 0.27 & 1.47 & 0.68 & 0.18 & 289 \\
PLT & 110 & $54,661,727$ & $190,604.2$ & $3,215,310$ & 289 \\
RETE & 0.06 & 0.3 & 0.19 & 0.04 & 289 \\
NU & 0 & 91 & 8.74 & 15.02 & 289 \\
RTS & 0 & $13,964,015$ & $465,725.7$ & $979,115.3$ & 289 \\
NIAS & 0 & 849 & 103.06 & 110.6 & 289 \\
\hline
\end{tabular}


Table 6. Ordinary least squares (OLS) and geographically weighted regression (GWR) regression results.

\begin{tabular}{|c|c|c|c|c|c|c|}
\hline \multirow{2}{*}{ Parameters } & \multicolumn{2}{|c|}{ Model 1} & \multicolumn{4}{|c|}{ Model 2} \\
\hline & Coeff. & Std. Err. & Lower Quartile & Median & Upper Quartile & Sig. $(P<0.05)$ \\
\hline ln Aggro_agro & $-0.202 * * *$ & 0.029 & -0.213 & -0.154 & -0.107 & $76 \%$ \\
\hline ln Aggro_manu & $0.446^{* * *}$ & 0.078 & 0.285 & 0.371 & 0.532 & $66.8 \%$ \\
\hline ln Aggro_elec & $-0.33^{* * *}$ & 0.078 & -0.332 & -0.14 & 0.039 & $29.1 \%$ \\
\hline ln Aggro_cons & 0.064 & 0.06 & -0.021 & 0.083 & 0.141 & $16.6 \%$ \\
\hline ln Aggro_whol & 0.101 & 0.098 & -0.033 & 0.108 & 0.288 & $14.9 \%$ \\
\hline ln Aggro_trans & $0.164 *$ & 0.097 & -0.092 & -0.009 & 0.215 & $1.4 \%$ \\
\hline ln Aggro_hotel & -0.018 & 0.067 & -0.121 & -0.048 & -0.001 & $3.8 \%$ \\
\hline ln Aggro_infor & -0.117 & 0.095 & -0.226 & -0.036 & 0.07 & $4.5 \%$ \\
\hline ln Aggro_finan & 0.059 & 0.097 & -0.146 & -0.02 & 0.03 & $3.1 \%$ \\
\hline ln Aggro_real & $0.173 * *$ & 0.086 & -0.019 & 0.088 & 0.172 & $0.7 \%$ \\
\hline ln Aggro_leas & -0.01 & 0.064 & -0.042 & 0.115 & 0.194 & $13.1 \%$ \\
\hline ln Aggro_scien & $0.125 * *$ & 0.063 & -0.027 & 0.034 & 0.124 & $2.1 \%$ \\
\hline $\ln$ IPE & 0.127 & 0.128 & -0.418 & -0.244 & -0.124 & $9.3 \%$ \\
\hline $\ln \mathrm{ABD}$ & $0.114^{* *}$ & 0.055 & 0.288 & 0.409 & 0.558 & $65.1 \%$ \\
\hline $\ln \mathrm{DRN}$ & $0.159 * * *$ & 0.045 & -0.047 & 0.122 & 0.175 & $4.2 \%$ \\
\hline $\ln$ FDI & $0.115^{* * *}$ & 0.026 & 0.004 & 0.051 & 0.086 & $8.3 \%$ \\
\hline $\ln$ IFA & -0.01 & 0.045 & -0.082 & -0.022 & 0.048 & $1.7 \%$ \\
\hline $\ln \mathrm{LDR}$ & -0.111 & 0.105 & 0.043 & 0.181 & 0.339 & 0 \\
\hline $\ln$ PLT & $0.179^{* * *}$ & 0.042 & 0.149 & 0.251 & 0.358 & $65.1 \%$ \\
\hline ln RETE & -0.003 & 0.041 & -0.176 & -0.024 & 0.064 & $1.4 \%$ \\
\hline $\ln \mathrm{NU}$ & $0.076 * *$ & 0.03 & -0.014 & 0.031 & 0.072 & $3.1 \%$ \\
\hline ln RTS & 0.016 & 0.029 & -0.073 & -0.027 & 0.01 & $0.7 \%$ \\
\hline ln NIAS & -0.018 & 0.033 & -0.142 & -0.009 & 0.019 & $4.8 \%$ \\
\hline Intercept & 2.436 & 1.473 & 3.936 & 6.207 & 8.631 & $36.7 \%$ \\
\hline Global adj. $R^{2}$ & \multicolumn{2}{|c|}{0.787} & & & & \\
\hline Local $R^{2}$ & \multirow{2}{*}{\multicolumn{2}{|c|}{572}} & 0.848 & 0.87 & 0.897 & \\
\hline AIC & & & \multicolumn{4}{|c|}{521} \\
\hline
\end{tabular}

\subsubsection{Effect of Industrial Agglomeration on LUE}

Figure 5 shows the spatial distribution of local $R^{2}$ in the results. The values of local $R^{2}$ of the central areas are lower than those of the north and south areas. Clearly, all the cities have a local $R^{2}$ in the range of $77 \%$ to $92.2 \%$. Thus, the GWR model has good fitting results in terms of the estimates. Figure 6 shows that the impacts of industrial agglomeration of detailed sectors on LUE vary. Under this condition, the effects of detailed sectors on LUE are analyzed as follows.

Agro-Industry

The agglomeration of the agro-industry has a remarkably negative effect on LUE across the country. The level of these negative effects in the eastern coastal and southwest areas is lower than that in the central and north areas, which range from -0.367 to -0.046 . P-values in $76 \%$ of the cities are significant at the $5 \%$ level, indicating that the negative effects of agro-industry concentration on LUE in most areas are significant. This condition reflects the dilemma of land management in China. On the basis of its own properties and the deficiency of high technology application, the economic benefits of agriculture cannot compete with the performance of non-agricultural sectors, which have led many farmers to look for non-agricultural jobs. By contrast, non-agricultural industries, such as tourism and catering services, are not allowed to develop on agricultural land to ensure food security. Especially in peri-urban areas, low LUE of agriculture usually implies that agricultural development would give way to non-agricultural industries. This scenario is non-beneficial for the modernization of urban agriculture.

\section{Manufacturing}

The aggregation of manufacturing has a prominently positive effect on LUE. Thus, the denser the urban manufacturing becomes, the higher the LUE will be. The value of the coefficients ranges from 0.136 to 1.012. P-values show that the benefits of manufacturing on LUE in $66.8 \%$ of the cities 
are significant at the 5\% level. Based on the spatial distribution of the effect on manufacturing, agglomerations of manufacturing in YRD and its surrounded areas have the highest positive impacts on the output of land and have a lower effect in majority of the northern and central areas. Furthermore, PRD, which is a traditional manufacturing region, shows a much lower effect than YRD. Therefore, the manufacturing agglomeration has much higher externalities for land output in YRD. This situation reflects the fact that the YRD has been gradually replacing PRD to take the lead in manufacturing in China.

\section{Electricity and Gas}

The agglomeration of the electricity and gas industry has a positive impact on LUE in YRD and surrounding cities in Shandong, Henan, Hubei and Jiangxi provinces. However, it has a negative impact in some cities in the northeast and southwest regions. The values of the effect are between -0.732 and 0.31 . P-values are significant at the $5 \%$ level in $29.1 \%$ of the cities. Instead of promoting LUE, the aggregation of electricity and gas in Inner Mongolia, Gansu and Yunnan provinces indicates that land use of the electricity and gas industry in these areas is not efficient enough. Moreover, plenty of related natural resources perform a negative effect on LUE in these provinces.

\section{Construction}

The effects of construction agglomeration are positive in most eastern and central areas but negative in some western and northeast areas. The values of the coefficient range from -0.46 to 0.287. High value of construction agglomeration usually indicates a rapid urbanization development. Areas with high externalities of construction overlap the places with a high degree of construction LQ. P-values in $16.6 \%$ of the cities are significant at the $5 \%$ level.

\section{Wholesale and Retail Trade}

The concentration of wholesale and retail trade performs a negative impact on LUE in Henan Province and some cities in western regions. However, it has a positive effect on LUE in other cities, especially in Fujian Province and in the northeast region. The value of the externalities is between -0.167 and 0.5 . The middle areas of Hubei and Henan provinces display a high value of LQ, but the agglomeration of wholesale and retail trade negatively impact LUE in this area. This finding reflects that wholesale and retail trade is a labour-intensive industry with relatively less economic returns. P-values in $14.9 \%$ observations are significant at the $5 \%$ level.

\section{Transport, Storage, and Post Services}

The agglomeration of transport, storage and post services has negative externalities to LUE in the eastern and central areas and positive externalities in the western areas. The values of this external effect are between -0.231 and 0.366 . Western areas with less developed economies are likely dependent on this industrial sector, but the situation of the more developed areas are the opposite. P-values of the coefficients in only $1.4 \%$ of the cities are significant at the $5 \%$ level. Therefore, the effect of transport, storage and post services is unclear.

\section{Hotel and Catering Services}

The agglomeration of hotel and catering services has a remarkably positive effect on LUE mainly in the PRD and its surrounding cities and performs a negative impact in most cities in China. The values of the effect range from -0.338 to 0.116 . P-values of the coefficients in $3.8 \%$ of the cities are significant at the $5 \%$ level. Hotel and catering services are closely related with the development of tourism, which is a sunrise industry. At present, tourism in China is still at the early stages of development, and high-quality tourism products need to be developed in the future. The insignificance and negative 
effects of the agglomeration of hotel and catering services indicate that tourism does not play a powerful role in increasing LUE, but it has a great potential to develop.

Information and Software Services

The aggregation of information and software services has a greatly positive impact on LUE in PRD and its surrounding cities in Hunan and Guangxi provinces. It also has a slightly positive impact in western cities. However, it has a negative impact on LUE in YRD, BTH and northeast areas. The values of the effect are from -0.378 to 0.294 . Although BTH has a high value of the agglomeration of information and software services, the externality of agglomeration in the area is negative. P-values of the coefficient in $4.5 \%$ of the cities are significant at the $5 \%$ level.

\section{Financial Services}

The values of agglomerated effect of financial services on LUE range from -0.351 to 0.221 . The agglomeration of financial services performs a significant externality to LUE in the southwest region and some cities in the central region, whereas it has a negative impact in YRD and PRD. The spatial distribution of the effect contradicts the development of financial services. In $3.1 \%$ of the cities, p-values of the coefficient are significant at the $5 \%$ level.

\section{Real Estate}

The agglomeration of real estate performs a positive impact in BTH, PRD and most cities in the central and western areas. It is especially remarkable in the northwest and southwest areas but has a negative impact in YRD and its surrounding cities. Values of the coefficient range from -0.291 to 0.35 . Real estate is important to the local government because it increases the local off-budget, which heavily relies on land revenue [75]. Although several policies have been made to restrain exorbitant housing prices, real estate still has a large bubble, which may lead to financial crises. From the spatial distribution of the effect of real estate on LUE, BTH and Inner Mongolia, Gansu, Shaanxi, Guizhou, Yunnan and Guangxi provinces should focus on the real estate bubble and avoid being excessively dependent on the real estate.

Leasing and Business Services

The agglomeration of leasing and business services has a positive impact in eastern coastal areas, northeast region and central areas, but it has a negative effect in PRD and western areas. Values of the coefficient range from -0.318 to 0.323 . The positive impact is especially remarkable in YRD and some cities in Fujian province. Areas with the most serious negative effect are concentrated in Sichuan and Yunnan provinces. Leasing and business services are highly related to the level of urban development. Therefore, the high externality of leasing and business services to LUE in YRD indicates that YRD is the most active business center in China, and the return on investment in the area is very high. P-values of this coefficient in $13 \%$ of the cities are significant.

\section{Scientific Research and Technical Services}

The aggregation of scientific and technical services in most cities has a positive effect on LUE, especially in YRD and some cities in the northeast region. However, it has a negative impact only in western areas, BTH and surrounding cities. The values of the coefficient range from -0.337 to 0.249 . Although BTH has a dense agglomeration of scientific research and technical services, it has negative economic externality to LUE. This fact indicates that improving the output performance of scientific and technological achievement and its LUE is necessary. P-values of this coefficient in $2.1 \%$ of the cities are significant. 


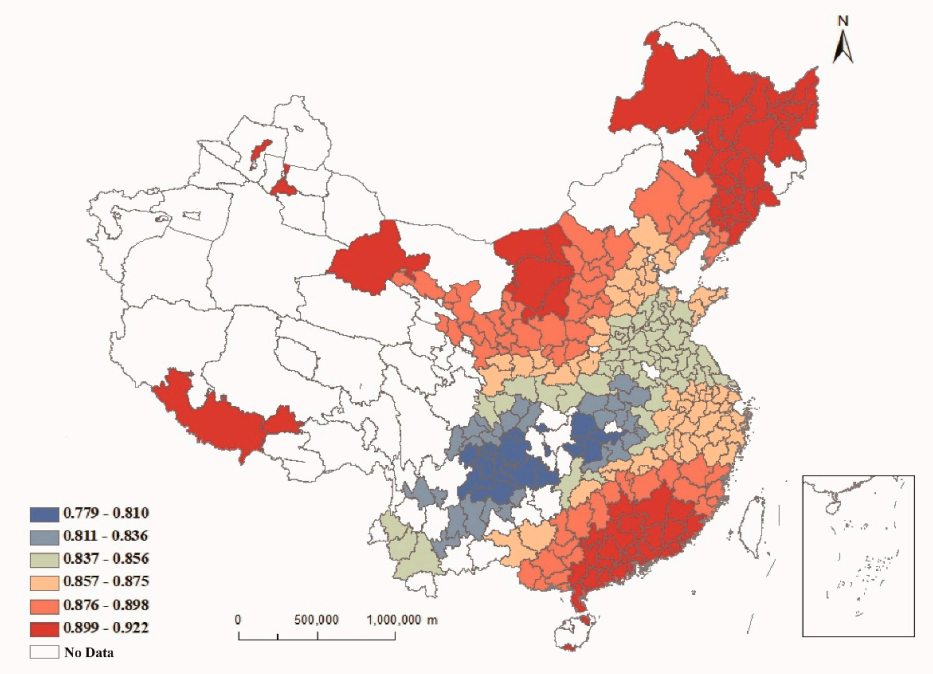

Figure 5. Spatial distribution of local $R^{2}$.
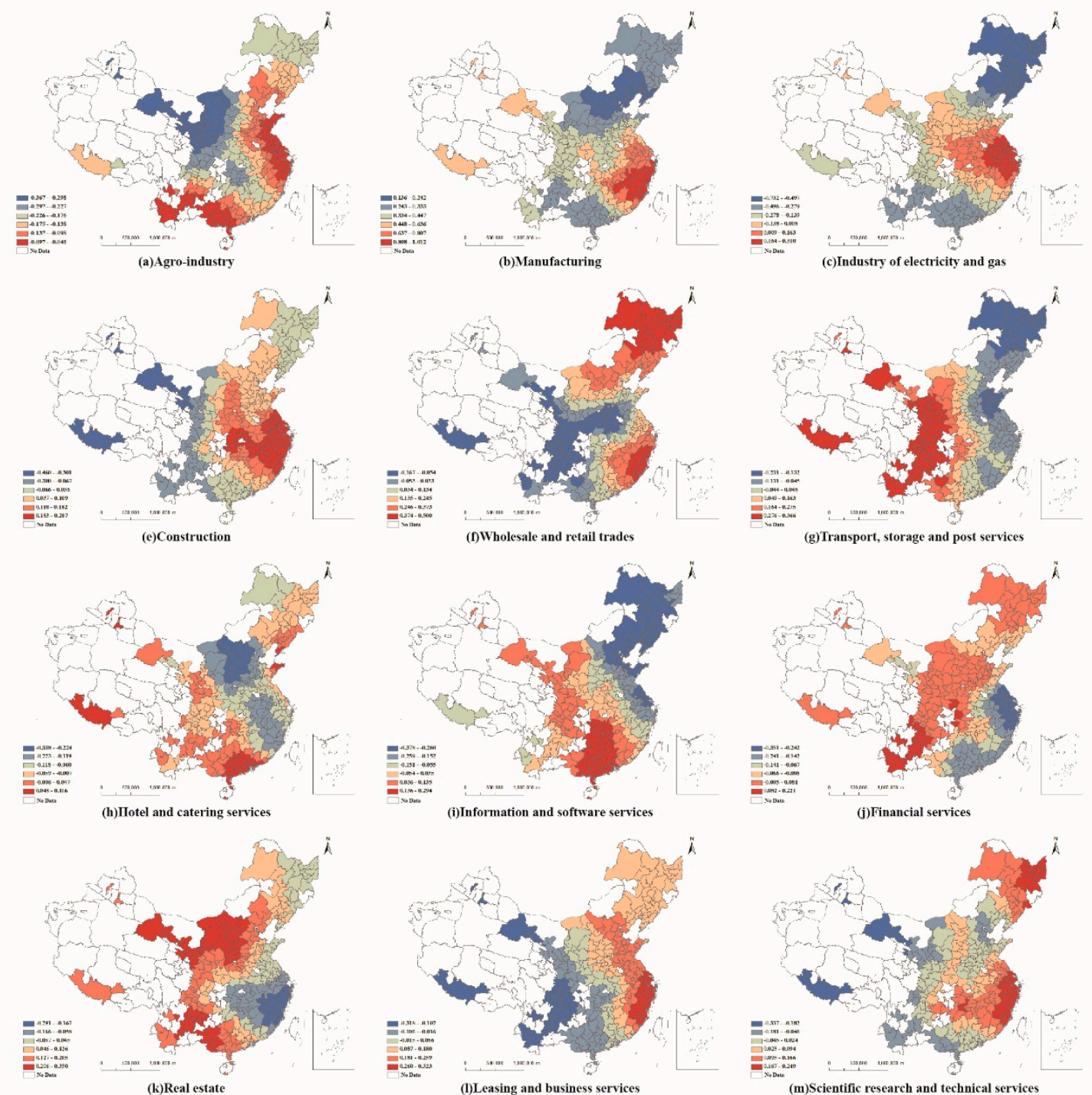

Figure 6. Spatial effects of detailed sectors on LUE. 


\section{Conclusions and Policy Implications}

The spatial distribution of industrial agglomeration of 12 sectors and LUE in 2016 is investigated. In accordance with the GWR model, the spatial effects of industrial agglomerations on LUE are explored. On the basis of the empirical findings, three main conclusions are obtained.

First, spatial economic effects of industrial agglomeration on LUE in city groups are evident. YRD is the region with the highest and most significant externalities of industrial agglomeration on LUE. In YRD, the agglomeration of several detailed sectors, including manufacturing, electricity and gas, construction, wholesale and retail trade, leasing and business services, and scientific research and technical services, have the highest positive effects on LUE. In PRD, aggregations of hotel and catering services and information and software services perform the most remarkably positive impacts on LUE. These results mean that land use in the two city groups is relatively reasonable. However, BTH, as the only city cluster in the coastal northern region of China, does not have a high return value of industry to land output. This means that its land use efficiency is still not high enough as it should be and have large room for improvement comparing with YRD and PRD.

Second, spatial patterns and distributions of industrial agglomeration effects on LUE vary across regions. Aggregations of agro-industry and hotel and catering services have negative impacts on LUE nationwide. Manufacturing has a positive effect on LUE in the whole country. However, other industries do not have coherent effects on LUE in space, which indicates there is still a huge gap between LUE and economic returns across cities in China. Individual city can then learn from their peer city to further improve its performance in land use efficiency through industrial agglomeration.

Third, the significance of industrial agglomeration effects on LUE between detailed sectors is different. The negative effect of agro-industrial agglomeration on LUE is significant. Among the secondary industries, manufacturing has a positive effect on LUE, indicating that the development of the manufacturing industry is still the main driver of economic efficiency in China. However, nearly all the detailed sectors among the services industries do not have significant effects on LUE yet. This situation indicates that the service industries still need to be advanced to have better economies of scale effect on LUE.

The results also have important policy implications for the economically more efficient urban development.

First, the modernization and industrialization of the urban agro-industry should be improved. In China, agriculture normally covers large areas but is characterized with low production and efficiency, especially in the central and western areas [76]. This sector is seen as unprofitable and needs financial support from the government. Therefore, increasing the value-added chain of urban agriculture is necessary. Integrations of agriculture and other industries, such as leisure, education, high-tech science, ecology and others, should be promoted.

Second, the LUE of service industries should be improved. The results of the GWR regression show that detailed sectors of the services industries do not have evident positive effects on LUE. With the high level of urbanization in the three main urban clusters, service industries have gradually become the dominant industries in these areas. However, service industries, such as hotel and catering, information and software and financial services, still have negative effects on LUE in coastal areas, indicating inefficient land use. Therefore, the productive efficiency and economies of scale effects of the service industries should be strengthened, and timely monitoring the urban expanding and industrial performance should be given careful attentions, for timely adjustment and adaptation to the introduction and application of any new technologies.

Third, efficient growth should be adopted by the government especially in BTH, YRD, and PRD. The three main urban clusters are the key economic development centers and engines in China. However, due to the large population, the land in eastern developed areas is usually limited and deficient. The disorderly large-scale urban constructions and urban sprawl in the past were also no longer economically feasible and sustainable. Therefore, future urban development in China should 
be focusing more on efficient growth and effective governance by introducing more compact land use instruments and smart agglomeration management.

Author Contributions: W.H. and J.C. proposed the research framework, drafted and finalized the paper. Y.Z. worked on the review and editing. E.M. worked on the resources. All authors have read and approved the final manuscript.

Acknowledgments: The authors are grateful for the financial support from the National Natural Science Foundation of China (No. 71734001), MOE (Ministry of Education in China) Project of Humanities and Social Sciences (No.18YJC840041) and State Ethnic Affairs Commission of China Project (No.2018-GMB-041). The authors gratefully the anonymous reviewers for insightful comments that helped us improve the quality of the paper.

Conflicts of Interest: The authors declare no conflict of interest in this paper.

\section{References}

1. Chen, W.; Shen, Y.; Wang, Y.; Wu, Q. The effect of industrial relocation on industrial land use efficiency in china: A spatial econometrics approach. J. Clean. Prod. 2018, 205, 525-535. [CrossRef]

2. Zhang, Q.; Sun, Z.; Huang, W. Does land perform well for corn planting? An empirical study on land use efficiency in china. Land Use Policy 2018, 74, 273-280. [CrossRef]

3. Lu, X.; Kuang, B.; Li, J. Regional difference decomposition and policy implications of china's urban land use efficiency under the environmental restriction. Habitat Int. 2018, 77, 32-39. [CrossRef]

4. Du, J.; Thill, J.-C.; Peiser, R.B. Land pricing and its impact on land use efficiency in post-land-reform china: A case study of beijing. Cities 2016, 50, 68-74. [CrossRef]

5. Tu, F.; Yu, X.; Ruan, J. Industrial land use efficiency under government intervention: Evidence from hangzhou, china. Habitat Int. 2014, 43, 1-10. [CrossRef]

6. Porter, M.E. On Competition; Harvard Business School Press: Cambridge, UK, 1998.

7. Swann, P.; Prevezer, M. A comparison of the dynamics of industrial clustering in computing and biotechnology. Res. Policy 1996, 25, 1139-1157. [CrossRef]

8. Glaeser, E.L.; Kallal, H.D.; Scheinkman, J.A.; Shleifer, A. Growth in cities. J. Polit. Econ. 1992, 100, 1126-1152. [CrossRef]

9. Marshall. Principles of Economics; MacMillan: London, UK, 1890.

10. Arrow, K.J. The economic implications of learning by doing. Rev. Econ. Stud. 1962, 29, 155-173. [CrossRef]

11. Romer, P.M. Endogenous technological change. J. Polit. Econ. 1990, 98, S71-S102. [CrossRef]

12. Zheng, Q.; Lin, B. Impact of industrial agglomeration on energy efficiency in china's paper industry. J. Clean. Prod. 2018, 184, 1072-1080. [CrossRef]

13. Cabral, L.; Wang, Z.; Xu, D.Y. Competitors, complementors, parents and places: Explaining regional agglomeration in the U.S. Auto industry 放. Rev. Econ. Dyn. 2013, 30, 1-29. [CrossRef]

14. Brunello, G.; Langella, M. Local agglomeration, entrepreneurship and the 2008 recession: Evidence from italian industrial districts. Reg. Sci. Urban Econ. 2016, 58, 104-114. [CrossRef]

15. Jacobs, J. The Economy of Cities; Retrieved; Vintage: New York, NY, USA, 1969.

16. Scott, R. The New Role of American States; Oxford University Press: Oxford, UK, 1988.

17. Weber, A. Ber Den Standort Der Industrie, Mohr, Tübingen; University of Chicago Press: Chicago, IL, USA, 1909. (In German)

18. Friedrich, C.J. Alfred Weber's Theory of the Location of Industries; The University of Chicago Press: Chicago, IL, USA, 1929.

19. Christaller, W. Die Zentralen Orte in Süddeutschland; Prentice-Hall: Englewood Cliffs, NJ, USA, 1933.

20. Lösch, A. Die Raumliche Ordnung der Wirtshcaft; Yale University: New Haven, CN, USA, 1941.

21. Mulligan, G.F. Central place theory and its reemergence in regional science. Ann. Reg. Sci. 2012, 48, 405-431. [CrossRef]

22. Thabet, K. Industrial structure and total factor productivity: The tunisian manufacturing sector between 1998 and 2004. Ann. Reg. Sci. 2015, 54, 639-662. [CrossRef]

23. Ciccone, A. Agglomeration effects in europe. Eur. Econ. Rev. 2002, 46, 213-227. [CrossRef]

24. Cingano, F.; Schivardi, F. Identifying the sources of local productivity growth. J. Eur. Econ. Assoc. 2004, 2, 720-742. [CrossRef] 
25. Martin, P.; Mayer, T.; Mayneris, F. Spatial concentration and plant-level productivity in France. J. Urban Econ. 2011, 69, 182-195. [CrossRef]

26. Zhang, H. How does agglomeration promote the product innovation of chinese firms? China Econ. Rev. 2015, 35, 105-120. [CrossRef]

27. Fafchamps, M.; Hamine, S.E. Firm productivity, wages, and agglomeration externalities. Res. Econ. 2017, 71, 291-305. [CrossRef]

28. Liang, J.; Goetz, S.J. Technology intensity and agglomeration economies. Res. Policy 2018, 47, $1990-1995$. [CrossRef]

29. Combes, P. Economic structure and local growth: France, 1984-1993. J. Urban Econ. 2000, 47, 329-355. [CrossRef]

30. Fan, C.C.; Scott, A.J. Industrial agglomeration and development: A survey of spatial economic issues in east asia and a statistical analysis of chinese regions. Econ. Geogr. 2003, 79, 295-319. [CrossRef]

31. Han, F.; Xie, R.; Fang, J. Urban agglomeration economies and industrial energy efficiency. Energy 2018, 162, 45-59. [CrossRef]

32. Batisse, C. Dynamic externalities and local growth: A panel data analysis applied to chinese provinces. China Econ. Rev. 2002, 13, 231-251. [CrossRef]

33. Cerina, F.; Mureddu, F. Is agglomeration really good for growth? Global efficiency, interregional equity and uneven growth. J. Urban Econ. 2014, 84, 9-22. [CrossRef]

34. Chen, Y.; Chen, Z.; Xu, G.; Tian, Z. Built-up land efficiency in urban china: Insights from the general land use plan (2006-2020). Habitat Int. 2016, 51, 31-38. [CrossRef]

35. Xie, H.; Chen, Q.; Lu, F.; Wu, Q.; Wang, W. Spatial-temporal disparities, saving potential and influential factors of industrial land use efficiency: A case study in urban agglomeration in the middle reaches of the yangtze river. Land Use Policy 2018, 75, 518-529. [CrossRef]

36. Graham, D.J.; Kim, H.Y. An empirical analytical framework for agglomeration economies. Ann. Reg. Sci. 2008, 42, 267-289. [CrossRef]

37. Combes, P.; Duranton, G.; Overman, H.G. Agglomeration and the adjustment of the spatial economy. Pap. Reg. Sci. 2010, 84, 311-349. [CrossRef]

38. Ke, S. Agglomeration, productivity, and spatial spillovers across chinese cities. Ann. Reg. Sci. 2010, 45, 157-179. [CrossRef]

39. Brülhart, M.; Mathys, N.A. Sectoral agglomeration economies in a panel of european regions «r. Reg. Sci. Urban Econ. 2008, 38, 348-362. [CrossRef]

40. Huang, Z.; Wei, Y.D.; He, C.; Li, H. Urban land expansion under economic transition in china: A multi-level modeling analysis. Habitat Int. 2015, 47, 69-82. [CrossRef]

41. Wu, C.; Wei, Y.D.; Huang, X.; Chen, B. Economic transition, spatial development and urban land use efficiency in the yangtze river delta, china. Habitat Int. 2017, 63, 67-78. [CrossRef]

42. Wei, Y.D. Decentralization, marketization, and globalization: The triple processes underlying regional development in china. Asian Geogr. 2001, 20, 7-23. [CrossRef]

43. Canfei, H.E.; Zhu, S. Economic transition and industrial restructuring in china: Structural convergence or divergence? Post-Commun. Econ. 2007, 19, 317-342. [CrossRef]

44. Deng, F.F. China's urban land reform, urban productivity, and local government behavior. Eurasian Geogr. Econ. 2003, 44, 210-227. [CrossRef]

45. Zhou, D.; Xu, J.; Li, W.; Lin, Z. Assessing urbanization quality using structure and function analyses: A case study of the urban agglomeration around hangzhou bay (uahb), china. Habitat Int. 2015, 49, 165-176. [CrossRef]

46. Long, H.; Zou, J.; Liu, Y. Differentiation of rural development driven by industrialization and urbanization in eastern coastal china. Habitat Int. 2009, 33, 454-462. [CrossRef]

47. Gao, J.; Wei, Y.D.; Chen, W.; Chen, J. Economic transition and urban land expansion in provincial china. Habitat Int. 2014, 44, 461-473. [CrossRef]

48. Wei, Y.H.D. Restructuring for growth in urban china: Transitional institutions, urban development, and spatial transformation. Habitat Int. 2012, 36, 396-405. [CrossRef]

49. Wang, Z.; Chen, J.; Zheng, W.; Deng, X. Dynamics of land use efficiency with ecological intercorrelation in regional development. Landsc. Urban Plan. 2018, 177, 303-316. [CrossRef] 
50. Huang, L. From benign unconstitutionality to delegated legislation: Analysis on the ways for legal reform of china rural collective construction land circulation. Habitat Int. 2018, 74, 36-47. [CrossRef]

51. Huang, D.; Chan, R.C.K. On 'land finance' in urban china: Theory and practice. Habitat Int. 2018, 75, 96-104. [CrossRef]

52. Rongyu, W.; Rong, T. Efficiency and distribution of rural construction land marketization in contemporary china. China Econ. Rev 2018. in Press.

53. Azari, M.; Kim, H.; Kim, J.Y.; Ryu, D. The effect of agglomeration on the productivity of urban manufacturing sectors in a leading emerging economy. Econ. Syst. 2016, 40, 422-432. [CrossRef]

54. Miller, S.M.; Upadhyay, M.P. The effects of openness, trade orientation, and human capital on total factor productivity. J. Dev. Econ. 2000, 63, 399-423. [CrossRef]

55. Liu, C.; Wang, W.; Wu, Q. Transportation Infrastructure, Competition and Productivity: Theory and Evidence from China; Social Science Electronic Publishing: New York, NY, USA, 2018.

56. Nadiri, M.I.; Nandi, B.; Akoz, K.K. Impact of modern communication infrastructure on productivity, production structure and factor demands of us industries: Impact revisited. Telecommun. Policy 2018. [CrossRef]

57. Mattsson, P. The impact of labour subsidies on total factor productivity and profit per employee. Econ. Anal. Policy 2018, in press. [CrossRef]

58. Brunsdon, C.; Fotheringham, A.S.; Charlton, M.E. Geographically weighted regression: A method for exploring spatial nonstationarity. Geogr. Anal. 1996, 28, 281-298. [CrossRef]

59. Tenerelli, P.; Demšar, U.; Luque, S. Crowdsourcing indicators for cultural ecosystem services: A geographically weighted approach for mountain landscapes. Ecol. Indic. 2016, 64, 237-248. [CrossRef]

60. Chen, W.; Shen, Y.; Wang, Y. Does industrial land price lead to industrial diffusion in china? An empirical study from a spatial perspective. Sustain. Cities Soc. 2018, 40, 307-316. [CrossRef]

61. Li, C.; Li, F.; Wu, Z.; Cheng, J. Exploring spatially varying and scale-dependent relationships between soil contamination and landscape patterns using geographically weighted regression. Appl. Geogr. 2017, 82, 101-114. [CrossRef]

62. Da Silva, A.R.; Mendes, F.F. On comparing some algorithms for finding the optimal bandwidth in geographically weighted regression. Appl. Soft Comput. 2018, 73, 943-957. [CrossRef]

63. Nilsson, P. Natural amenities in urban space-A geographically weighted regression approach. Landsc. Urban Plan. 2014, 121, 45-54. [CrossRef]

64. Bowman, A.W. An alternative method of cross-validation for the smoothing of density estimates. Biometrika 1984, 71, 353-360. [CrossRef]

65. Cleveland, W.; Devlin, S. Locally weighted regression: An approach to regression analysis by local fitting. Publ. Am. Stat. Assoc. 1988, 83, 596-610. [CrossRef]

66. Rothwell, A.; Ridoutt, B.; Page, G.; Bellotti, W. Environmental performance of local food: Trade-offs and implications for climate resilience in a developed city. J. Clean. Prod. 2016, 114, 420-430. [CrossRef]

67. Eigenbrod, C.; Gruda, N. Urban vegetable for food security in cities. A review. Agron. Sustain. Dev. 2015, 35, 483-498. [CrossRef]

68. Pérez-Neira, D.; Grollmus-Venegas, A. Life-cycle energy assessment and carbon footprint of peri-urban horticulture. A comparative case study of local food systems in spain. Landsc. Urban Plan. 2018, 172, 60-68. [CrossRef]

69. Yu, Q.; Wu, W.; Verburg, P.H.; van Vliet, J.; Yang, P.; Zhou, Q.; Tang, H. A survey-based exploration of land-system dynamics in an agricultural region of northeast china. Agric. Syst. 2013, 121, 106-116. [CrossRef]

70. Cheng, C.; Chen, F.; Li, G.; Ristić, B.; Mirchi, A.; Qiyu, T.; Madani, K. Reform and renewables in china: The architecture of yunnan's hydropower dominated electricity market. Renew. Sustain. Energy Rev. 2018, 94, 682-693. [CrossRef]

71. Liu, F.; Sun, F.; Liu, W.; Wang, T.; Wang, H.; Wang, X.; Lim, W.H. On wind speed pattern and energy potential in china. Appl. Energy 2019, 236, 867-876. [CrossRef]

72. Sun, X.; Geng-Qing Chi, C.; Xu, H. Developing destination loyalty: The case of hainan island. Ann. Tour. Res. 2013, 43, 547-577. [CrossRef]

73. Deng, X.; Gibson, J.; Pei, W. Relationship between landscape diversity and crop production: A case study in the hebei province of china based on multi-source data integration. J. Clean. Prod. 2017, 142, 985-992. [CrossRef] 
74. Zhao, Z.; Bai, Y.; Wang, G.; Chen, J.; Yu, J.; Liu, W. Land eco-efficiency for new-type urbanization in the beijing-tianjin-hebei region. Technol. Forecast. Soc. Chang. 2018, 137, 19-26. [CrossRef]

75. Zhao, S.X.B.; Zhan, H.; Jiang, Y.; Pan, W. How big is china's real estate bubble and why hasn't it burst yet? Land Use Policy 2017, 64, 153-162. [CrossRef]

76. Wu, Y. Productivity growth, technological progress, and technical efficiency change in china: A three-sector analysis 1. J. Comp. Econ. 1995, 21, 207-229. [CrossRef]

(c)

(C) 2019 by the authors. Licensee MDPI, Basel, Switzerland. This article is an open access article distributed under the terms and conditions of the Creative Commons Attribution (CC BY) license (http://creativecommons.org/licenses/by/4.0/). 